\title{
Selective Intracellular Delivery of Thiolated Cargo to Tumor and Neovasculature Cells Using Histidine-Rich Peptides as Vectors
}

\author{
J. Johannes Eksteen, Dominik Ausbacher, Terje Vasskog, Øystein Rekdal, and John S. M. Svendsen*
}

Cite This: ACS Omega 2020, 5, 4937-4942

Read Online

ABSTRACT: Short histidine-rich peptides could serve as novel activatable vectors for delivering cytotoxic payloads to tumor and neovasculature cells. This explorative study reports preliminary results showing that zinc ions, which are found in elevated levels at neovasculature sites, can trigger the intracellular delivery of a short antimicrobial peptide when conjugated to a histidine-rich peptide through a disulfide bond. The importance of exofacial thiols in the mode of action of these disulfide-linked conjugates is also shown.

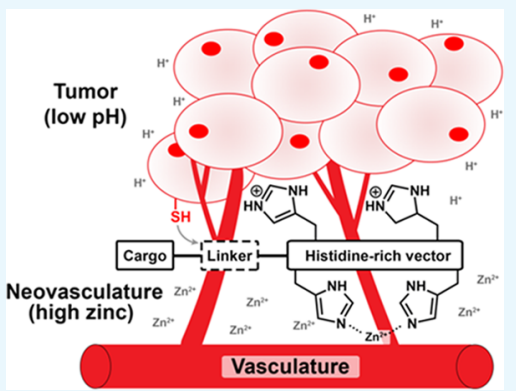

\section{INTRODUCTION}

The selective delivery of cytotoxic compounds to tumors following systemic administration is a subject that has been, and continues to be, the focus of many research groups. Numerous innovative targeting strategies have this far been identified, where the recurring theme is the exploitation of cellular and biochemical differences that exist between normal and cancer cells. ${ }^{1}$

One of these differences is the $\mathrm{pH}$ gradient that can be found between normal and tumor tissue. ${ }^{2,3}$ This phenomenon is due to the Warburg effect as well as the ineffective removal of acidic metabolic byproducts from tumor tissue. Strategies that exploit lower $\mathrm{pH}$ conditions typically involve the hydrolysis of acid-labile linkers or polymers resulting in the site-specific release of an active anticancer agent. ${ }^{1}$

A relatively new approach in the same vein is to take advantage of the facultative cationic character of histidine-rich peptides (HRPs). The imidazole moiety in histidine, with a $\mathrm{p} K_{\mathrm{a}}$ value of approximately 6 , is predominantly neutral under normal physiological conditions, but is readily protonated in the acidic microenvironment of a solid tumor. Consequently, the low $\mathrm{pH}$ can function as an activation trigger for a tumorspecific event. The usefulness of this concept was illustrated in studies where HRPs were shown to selectively lyse tumor cells in vivo ${ }^{4,5}$ and, more recently, were used as acid-catalyzed cellpenetrating peptides. ${ }^{6}$

Studies of the ubiquitous and multifunctional plasma protein, ${ }^{7}$ histidine-rich glycoprotein (HRGP), have revealed yet another activation trigger for HRPs. It was found that fragments of HRGP can acquire cationic charge not only by protonation but also through metal ion chelation. ${ }^{8,9}$ The normal concentration of $\mathrm{Zn}^{2+}$ found in plasma is too low for HRGP activation, but it was shown that at angiogenic sites, the elevated levels (approximately $50 \mu \mathrm{M}$ ) of $\mathrm{Zn}^{2+}$ exist, which are high enough to provide HRGP with a functional environment. ${ }^{10}$ This localized increase of $\mathrm{Zn}^{2+}$ is mediated through activated platelets, which have been shown to aggregate at sites of angiogenesis. ${ }^{10,11}$ Having large amounts of $\mathrm{Zn}^{2+}$ sequestered in their $\alpha$-granules, ${ }^{12}$ platelets can, once activated, effectuate a substantial increase in microenvironmental $\mathrm{Zn}^{2+}$ concentrations through a process called degranulation. ${ }^{10}$

When activated, HRGP can subsequently bind to glycosaminoglycans ${ }^{13}$ and take part in the inhibition of angiogenesis. ${ }^{14-16}$ This observation led to short fragments of HRGP being investigated as potential inhibitors of angiogenesis. ${ }^{17}$

We propose that short HRPs could be used as vectors for the targeted delivery of a cytotoxic cargoes to angiogenic sites and solid tumors (see Figure 1). The acquisition of charge (via protonation and/or chelation) will allow the vector to interact electrostatically with glycosaminoglycans that are often overexpressed on cancer cell membranes. After being immobilized on the surface of a target cell, the cargo can then be transported into the cell via endocytosis.

In the present study, two units of HRGP's tandem repeat sequence, GHHPH, are used as a vector since it was reported to chelate $\mathrm{Zn}^{2+}$ with high affinity. ${ }^{18} \mathrm{~A}$ short antimicrobial peptide, RWRWRW or $(\mathrm{RW})_{3}$, was chosen as a cargo since a similar peptide was shown to have a cytotoxic effect after intracellular delivery. ${ }^{19} \mathrm{~A}$ disulfide linker was used to conjugate

Received: November 8, 2019

Accepted: January 23, 2020

Published: March 6, 2020 


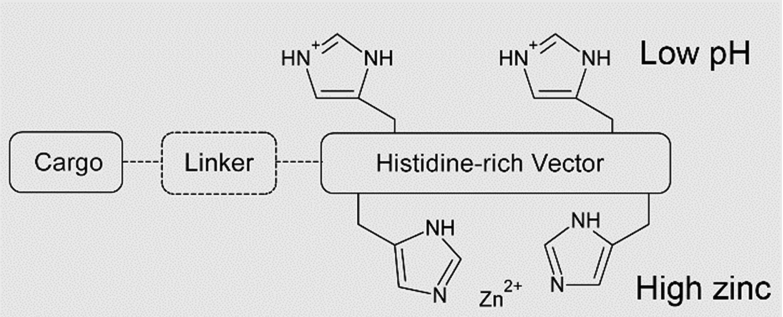

Figure 1. Multiple triggered delivery vector. Facultative cationic histidine-rich peptides could be activated by protonation (solid tumors) or chelation of $\mathrm{Zn}^{2+}$ ions (angiogenic sites).

the vector and cargo as this will result in the release of the cargo upon reduction. Our hypotheses were tested by screening for cytotoxic activity (MTT assay) against prostate carcinoma cells using elevated $\mathrm{Zn}^{2+}$ levels as the trigger.

\section{RESULTS AND DISCUSSION}

$(\mathrm{RW})_{3}$-amide (1) (see Figure $2 \mathrm{~A}$ ) is a short antimicrobial peptide (SAMP) with good activity against both Gram-positive
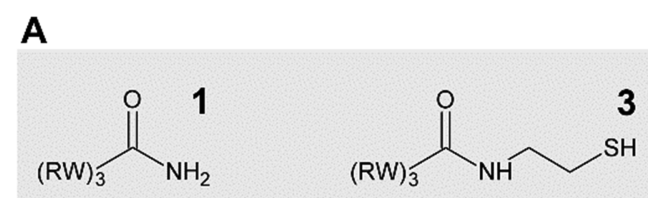

\section{B}
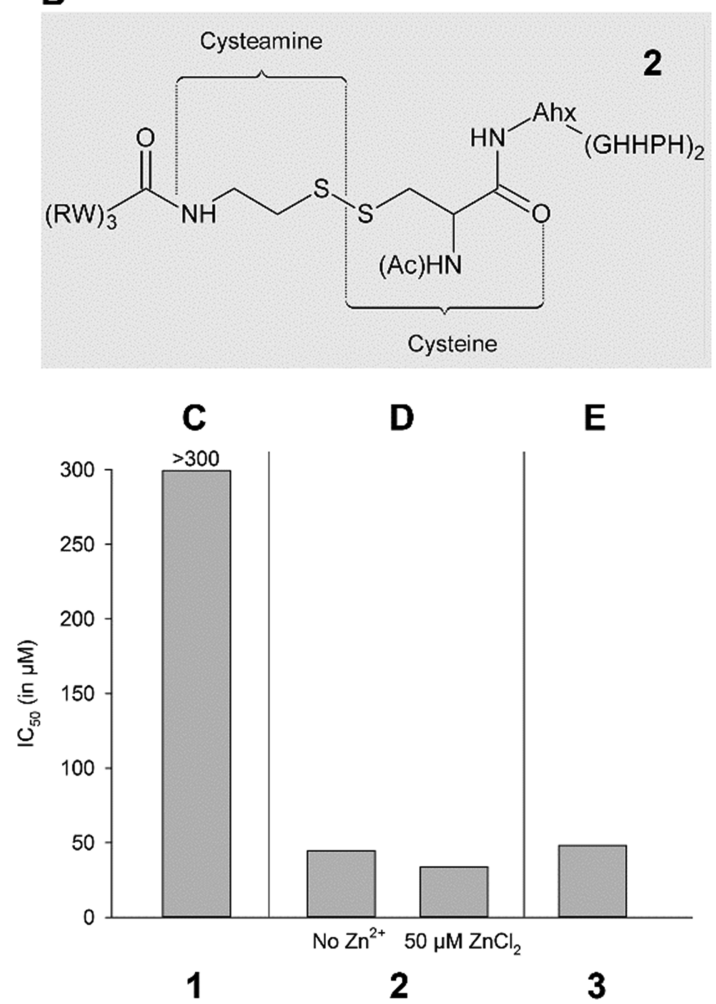

Figure 2. Converting a SAMP into an anticancer peptide. (A) $(\mathrm{RW})_{3}$ peptide, $\mathbf{1}$, and its thiolated analogue, 3 . (B) the cysteamine-cysteine disulfide linker system, 2. Cytotoxic effect against DU-145 prostate cancer cells measured as $\mathrm{IC}_{50}$ values for $(\mathrm{C})$ peptide $1,(\mathrm{D})$ peptide 2 in the absence or presence of $\mathrm{Zn}^{2+}$ ions, and $(\mathrm{E})$ peptide 3 . and Gram-negative bacteria without causing hemolysis. ${ }^{20}$ Its inactivity toward human red blood cells makes it an ideal candidate for systemic administration and transport.

When tested against DU-145 prostate cancer cells, peptide 1 did, as expected, show no signs of cytotoxicity (Figure 2C). The next step was to join an $(\mathrm{RW})_{3}$-peptide cargo peptide to an HRP-delivery vector peptide through an asymmetrical disulfide. The thiolated HRP-delivery vector was prepared by coupling a short HRGP fragment, $(\mathrm{GHHPH})_{2}$, with a spacer moiety (6-aminohexanoic acid, $\mathrm{Ahx}$ ) and a cysteine to its $\mathrm{N}$ terminus. To prepare for the disulfide linkage between the SAMP and vector, the C-terminus of $(\mathrm{RW})_{3}$ was functionalized with cysteamine, (peptide 3, see Figure 1A). The SAMP and HRP vector were conjugated to yield the complete cargolinker-vector peptide 2 (see Figure 2B). When this disulfide conjugate peptide was tested against DU-145 cells under elevated $\mathrm{Zn}^{2+}(50 \mu \mathrm{M})$ conditions, $\mathrm{IC}_{50}$ values below $50 \mu \mathrm{M}$ were seen (Figure 2D), seemingly confirming the concept. However, repeating the cytotoxicity assay in the absence of $\mathrm{Zn}^{2+}$ ions yielded, surprisingly, near identical $\mathrm{IC}_{50}$ values.

One possible hypothesis explaining the $\mathrm{Zn}^{2+}$ independence of peptide $\mathbf{2}$ is that the HRP-delivery vector was lost during the assay by reduction of the disulfide and that the observed cytotoxicity was due to the prematurely liberated thiolated cargo peptide 3 . To test this hypothesis, peptide 3 was tested separately against DU-145 cells and a cytotoxic effect on a similar level as peptide 2 was observed (Figure 2E).

To exclude that the observed activity was caused by the vector component, (GHHPG) $)_{2}$ was tested by itself under normal or elevated $\mathrm{Zn}^{2+}$ conditions. No activity was seen (results not shown), hence proving that the cytotoxicity is caused by the SAMP component alone.

As further substantiation that the $(\mathrm{RW})_{3}$-thiol cargo was the source of the observed cytotoxic activity, it was replaced with an inactive peptide, (EA) ${ }_{3}$-thiol, and tested. Once again, no activity was observed (results not shown).

The $\mathrm{Zn}^{2+}$ independence of the cytotoxicity of the complete cargo-linker-vector peptide $\mathbf{2}$ shows that the cysteaminecysteine linker is not fit for purpose in a selective delivery system.

However, this result did give some insight into how peptides 2 and 3 are causing cell death. The fact that they have similar $\mathrm{IC}_{50}$ values might suggest a common mode of action involving cell surface thiols.

Several extracellular membrane proteins contain thiols, most notably protein disulfide isomerase and thioredoxins, and these are thought to play important roles in extracellular redox control. Furthermore, it was previously reported that these extracellular or exofacial thiols can facilitate or enhance the ability of disulfide- and thiol-containing peptides to translocate across cell membranes. ${ }^{21,22}$

Thus, it could be hypothesized that once peptide 3 becomes covalently attached to a membrane protein, it will subsequently be endocytosed making it possible to interact with an internal target (e.g., the lysosome or endoplasmic reticulum ${ }^{19}$ ) resulting in cell death. This hypothesis could also explain why peptide $\mathbf{1}$ is not exhibiting cytotoxicity, that is, the lack of a thiol group precludes transduction across the cell membrane in a similar manner. An oxidative formation of a disulfide bond between the cargo peptide 3 and exofacial thiols could therefore explain the cytotoxicity observed for this peptide. For the same disulfide formation to take place from the disulfide peptide $\mathbf{2}$, the likely mechanism is thiol-disulfide exchange 
reactions. At physiological $\mathrm{pH}$, a thiol can be deprotonated to become a thiolate group. Sufficiently nucleophilic, an exofacial thiolate can attack the disulfide bond in peptide 2 leading to a rearrangement, which results in a new (different) disulfide bond and thiolate group. Peptide 2 could thus become covalently attached to proteins on the surface of the cell forming similar structures as peptide 3 , thus explaining that similar cytotoxicities are observed with both peptides 2 and 3 . As can be seen from the chemical structure of the linker (Figure 2B), the disulfide is exposed with no neighboring groups shielding it from nucleophilic attack.

To pertinently investigate the linker system's stability and thiol-disulfide exchange theory, a second conjugate peptide was prepared. Replacing the cysteine in the HRP vector with penicillamine, a more sterically hindered disulfide linker was obtained. This vector has two sterically hindering methyl groups on the $\beta$-carbon adjacent to the sulfur atom, a feature that has previously been shown to improve the stability of disulfide linkers. ${ }^{23}$ When this new penicillamine conjugate, 4 (Figure 3A), was tested against DU-145 cells under normal and elevated $\mathrm{Zn}^{2+}$ conditions, a clear difference was seen (Figure 3C), where cytotoxic activity was only observed in the presence of $\mathrm{Zn}^{2+}$. The $\mathrm{IC}_{50}$ value obtained was similar to that of peptides 2 and 3 .

This result shows that employing a cargo-linker-vector peptide with a more stable disulfide bond requires $\mathrm{Zn}^{2+}$ activation before providing the cytotoxic effect. It seems that stronger ionic interaction between the peptide and cell membrane is needed before exchange reactions between surface thiols and sterically hindered disulfides can take place.

To further substantiate the relationship between cytotoxic activity and surface thiols, two additional experiments were performed. First, cells were preincubated with 5,5-dithio-bis(2nitrobenzoic acid) or DTNB, prior to treatment with the $\mathrm{Zn}^{2+}$ activated peptide 4 . DTNB is a cell impermeable disulfide reagent that blocks all accessible surface thiols. No activity was seen for peptide $\mathbf{4}$ against DTNB-pretreated cells (see Figure $3 \mathrm{C})$, further substantiating the need for free surface thiols for the cytotoxic effect.

Second, the cysteamine-penicillamine disulfide linker was replaced with a nonreducible linker. When this peptide, 5 (Figure 3B), was tested in the presence of $\mathrm{Zn}^{2+}$ and absence of DTNB, no activity was observed. This result not only confirms the role of surface thiols but also serves as proof that the activity seen is due only to the SAMP component and not the conjugate as a whole.

Next, the effect of linker stability on the kinetics of thioldisulfide exchange reactions was investigated. Glutathione is found both in reduced (GSH) and oxidized (GSSG) forms in the body. Because of the oxidizing conditions found in plasma, concentrations of GSH are quite low, while cytopolasmic levels tend to be much higher. ${ }^{24}$ To test the stability of the two linker systems, both disulfide conjugates were allowed to react with GSH. Two different concentrations were used to simulate extra- and intracellular conditions, and the reaction was followed using ultra performance liquid chromatography (UPLC). The stability is expressed as a linker reduction or $\mathrm{LR}_{50}$ value, that is, the time required to reduce the amount of intact linker by $50 \%$. The amount of intact conjugate was calculated and is presented in Figure 4. Both conjugates had lower $\mathrm{LR}_{50}$ values for higher GSH concentrations, and as expected, the sterically hindered cysteamine-penicillamine system is reduced significantly slower.

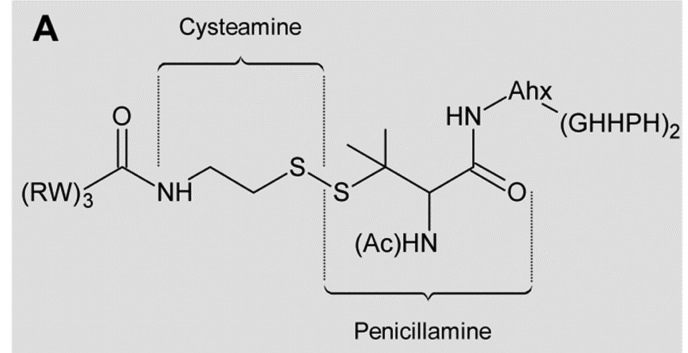

4

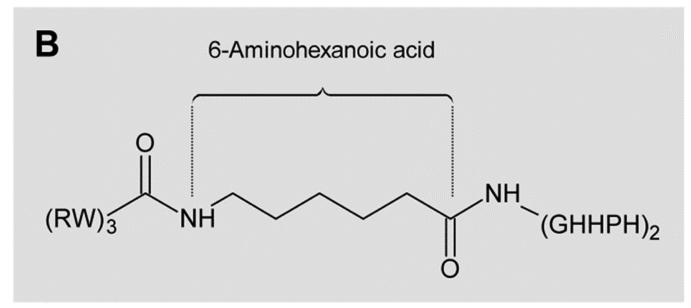

5

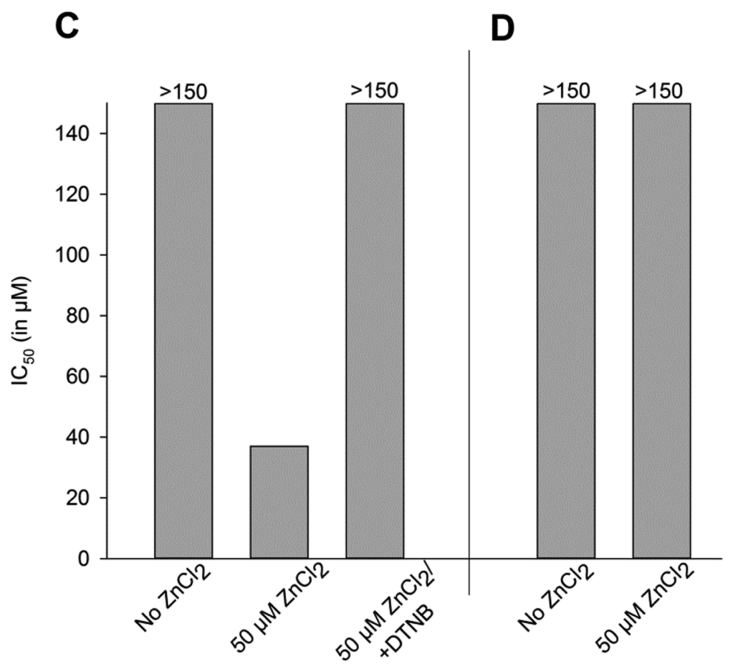

Figure 3. Cytotoxicity is thiol-mediated and caused by the SAMP cargo. (A) The sterically hindered cysteamine-penicillamine disulfide linker system, (B) nonreducible aminohexanoic linker, (C) cytotoxicity of peptide 4 upon $\mathrm{Zn}^{2+}$ activation but can be inhibited by capping exofacial thiols with DTNB, and (D) no cytotoxicity of peptide $\mathbf{5}$ when SAMP is irreversibly linked to vector.

Taking the cell viability and linker reduction results together, it is clear that $\mathbf{4}$ has a much better activation and cargo release profile than its labile cysteine analogue.

To better understand the mechanism by which 4 kills the cells, an electron microscopy study was performed. Cells were cultured as before and treated with peptide 4 for $24 \mathrm{~h}$ at a concentration of $27 \mu \mathrm{M}$ (approximately $0.75 \times \mathrm{IC}_{50}$ ). After the incubation period, the cells were collected, fixed and sections were prepared for transmission electron microscopy (TEM).

Analysis revealed a complete absence of morphology associated with classical apoptosis (i.e., membrane blebbing, disrupted mitochondria, and condensed DNA). Instead, peptide treatment resulted in massive vacuolization of the cells' cytoplasm (Figure 5B). Cytoplasmic vacuolization is a phenomenon often seen when cells are killed via the lysosomal membrane permeation (LMP) pathway. During LMP, proteolytic enzymes (e.g., cathepsins) are released in the 


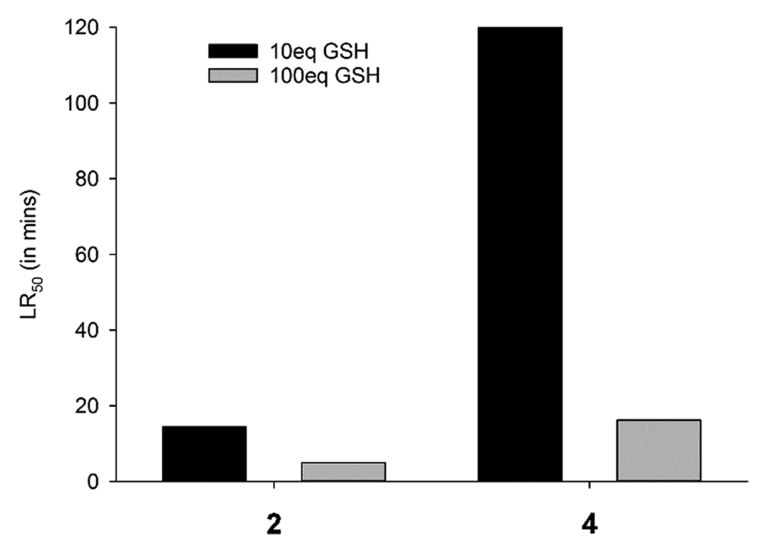

Figure 4. Modulating the stability of the linker toward thiol-disulfide exchange. In comparison with 2 , a significantly improved stability profile is seen for the sterically hindered penicillamine linker system of 4.

cytoplasm following membrane permeation/disintegration, resulting in a necrotic-like cell death. Although further experiments need to be done to confirm this hypothesis, it is worth to note that when a similar antimicrobial peptide (RRWQWR-amide) was transported into the cytoplasm of leukemia cells using fusogenic liposomes, a caspase-independent, cathepsin-mediated cell death was observed. ${ }^{19}$

\section{CONCLUSIONS}

This work has demonstrated that short antimicrobial peptides can be converted into anticancer compounds by simply incorporating a thiol group into their structure. This thiol allows the antimicrobial peptides to exert their cytotoxic properties by forming disulfide bonds with exofacial thiols. The results presented here suggest that (i) following extracellular thiol-disulfide exchange reactions, a thiolated SAMP is (ii) transported across the cancer cell membrane where it (iii) induces cell death via a mechanism that presumably involves the permeation of lysosomal membranes. However, this mechanism will not enable a targeted activity toward cancer cells. Selective activity on cancer cells can, however, be directed towards cancer calls using this fundamental property but only in combination with an appropriate targeting strategy.

This study has shown that the inherent cytotoxicity of a SAMP can simultaneously be masked and directed toward tumor and neovasculature cells by conjugation to a histidinerich vector via a sterically hindered disulfide linker system.

To fully assess the practical potential of this concept, further studies are required. First and foremost, it is important that spectroscopic and modeling studies are conducted to elucidate the manner by which the peptides interact and form complexes with $\mathrm{Zn}^{2+}$ ions. Second, the dual activatable nature of histinerich vectors is confirmed by testing the conjugates against cells adapted for growth at lower $\mathrm{pH}$ conditions. Also, conjugates with higher potency (i.e., lower $\mathrm{IC}_{50}$ values) will have to be designed and tested. Toward this end, current research in our group is focusing on cytotoxic peptidomimetics and small molecules as cargo elements.

If proven successful, this concept could potentially be developed into a general dual-activated delivery system for all types of thiol-containing cargos, enabling a new method of increasing tumor specific activity of anticancer agents, while simultaneously reducing the risk of systemic toxicity.

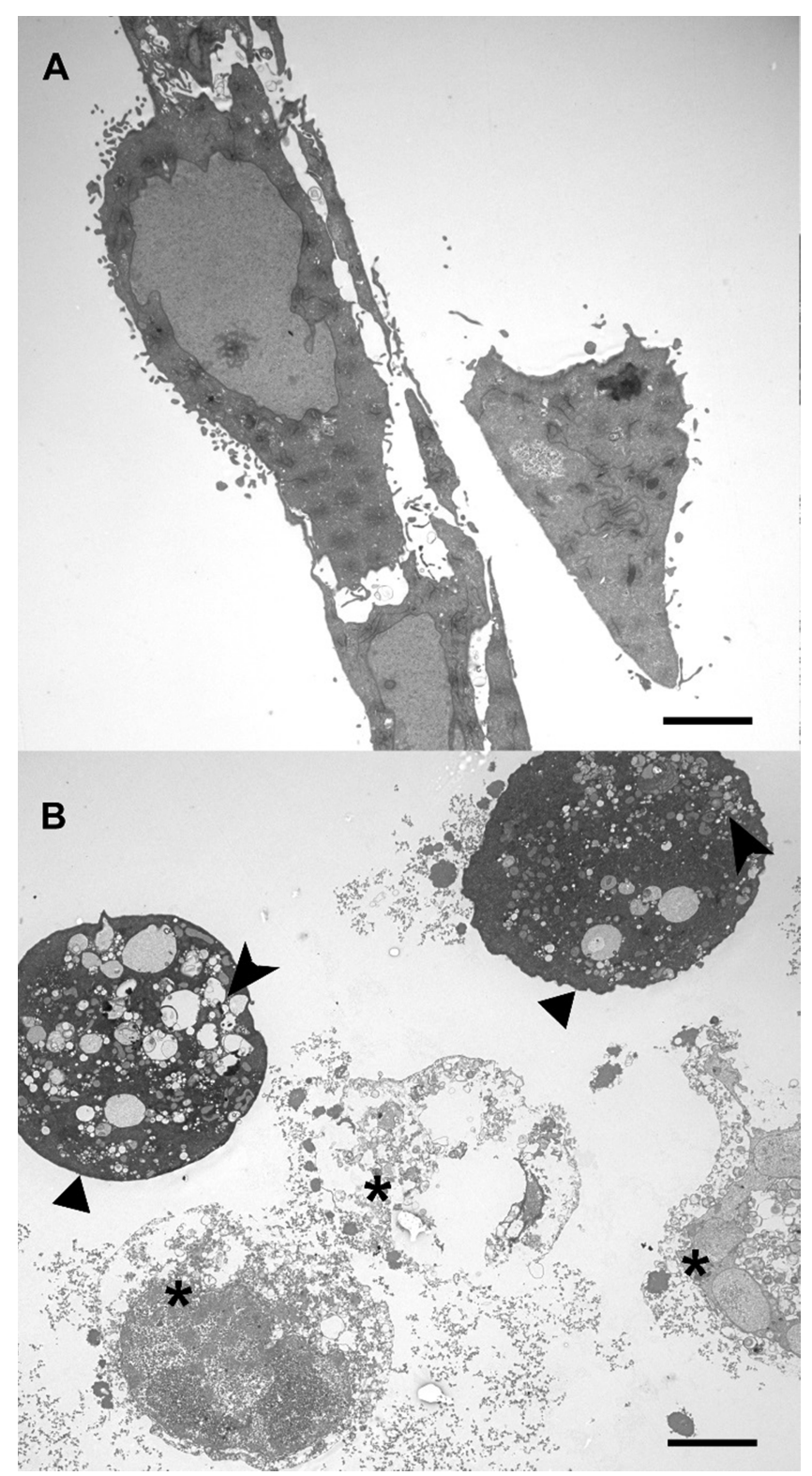

Figure 5. TEM micrographs showing (A) untreated DU-145 prostate cancer cells and (B) massive vacuolization after $24 \mathrm{~h}$ treatment with $\mathrm{Zn}^{2+}$ activated 4. Arrow heads indicate massive vacuolization, triangles indicate intact cell membranes, asterisks indicate necrotic cells.

\section{EXPERIMENTAL SECTION}

Peptide Synthesis. All peptides were synthesized by NORCE AS (Tromsø, Norway) following standard Fmocprotocols. Thiolated SAMPs were synthesized using a cysteamine 2-chlorotrityl resin. Vector peptides were Npysmodified during the final TFA cleavage step ${ }^{25}$ to yield a light straw-colored peptide. Crude peptides were purified by preparative HPLC (to $>95 \%$ purity) and lyophilized to yield TFA salts. Purity and correct molecular mass were confirmed by UPLC-PDA and time-of-flight mass spectrometry (ToF MS), respectively.

Conjugation Reactions. Asymmetrical disulfide peptides were prepared by conjugating the free thiol-containing SAMP and Npys-protected vector peptide in solution. Both components were dissolved in Milli- $Q$ water and mixed, and the $\mathrm{pH}$ was adjusted to 8 . The conjugation reaction, 
characterized by the development of a strong yellow color, was almost instantaneous (slower for the cysteamine-penicillamine disulfide). Directly after the reaction was completed, the $\mathrm{pH}$ was adjusted to 2 and the conjugation mixture purified using preparative HPLC.

In Vitro Assays. DU-145 prostate carcinoma cells were used in the biological evaluation of the peptides. The cells were cultivated in standard conditions $\left(37^{\circ} \mathrm{C}, 5 \% \mathrm{CO}_{2}\right)$. Afterward, cells were seeded in 96-well plates to a concentration of $1.5 \times$ $10^{5}$ cells per well. Following a $24 \mathrm{~h}$ peptide treatment, cell viability was determined using the well-established MTT assay.

The RPMI-1640 media was used to prepare peptide dilution series $(10-500 \mu \mathrm{g} / \mathrm{mL})$. To simulate elevated $\mathrm{Zn}^{2+}$ levels found at angiogenic sites, the media was adjusted with $50 \mu \mathrm{M}$ $\mathrm{ZnCl}_{2}$.

Exofacial thiols were blocked by preincubating cells for $1 \mathrm{~h}$ with RPMI-1640 containing $2.5 \mathrm{mM}$ DTNB. To ensure a thiolfree environment during the $24 \mathrm{~h}$ incubation period, the peptide dilution series were supplemented with $1 \mathrm{mM}$ DTNB.

Linker Reduction Assay. The stability of two disulfide conjugates toward GSH was determined in a kinetic assay. The peptides were dissolved in Milli-Q water to yield a stock solution of $1 \mathrm{mg} / \mathrm{mL}$. Two different conjugate:GSH ratios were tested (1:10 and 1:100). The conjugates were diluted with $100 \mathrm{mM}$ Tris ( $\mathrm{pH} 7.6$ ) to $50 \mu \mathrm{M}$ working solutions right before the start of the reaction. The GSH $(10 \mathrm{mM}$ in $100 \mathrm{mM}$ Tris, $\mathrm{pH}$ 7.6) was added, and the reaction was followed with UPLC. Samples were taken every $15 \mathrm{~min}$, and the reaction was monitored until all of the original disulfide conjugate disappeared. New peaks representing reduction byproducts were identified (by MS) and quantified (by UV).

Microscopy. DU-145 cells were treated with $\mathrm{Zn}^{2+}$ activated peptide 4 for $24 \mathrm{~h}$, collected, fixed, sectioned, and viewed using TEM.

\section{ASSOCIATED CONTENT}

\section{SI Supporting Information}

The Supporting Information is available free of charge at https://pubs.acs.org/doi/10.1021/acsomega.9b00700.

Detailed description of synthesis, peptide characterization, and in vitro and microscopy protocols (PDF)

\section{AUTHOR INFORMATION}

\section{Corresponding Author}

John S. M. Svendsen - Department of Chemistry, UiT Arctic University of Norway, NO 9037 Tromsø, Norway; (1) orcid.org/0000-0001-5945-6123; Phone: +47 776 44086; Email: john-sigurd.svendsen@uit.no

\footnotetext{
Authors

J. Johannes Eksteen - NORCE Norwegian Research Centre AS, Siva Innovasjonssenter, NO 9294 Tromsø, Norway; (1) orcid.org/0000-0002-5735-3582

Dominik Ausbacher - Department of Pharmacy, UiT Arctic University of Norway, NO 9037 Tromsø, Norway

Terje Vasskog - NORCE Norwegian Research Centre AS, Siva Innovasjonssenter, NO 9294 Tromsø, Norway

Øystein Rekdal - Lytix Biopharma AS, Siva Innovasjonssenter, NO 9294 Tromsø, Norway
}

Complete contact information is available at: https://pubs.acs.org/10.1021/acsomega.9b00700

\section{Author Contributions}

The manuscript was written through contributions of all authors. All authors have given approval to the final version of the manuscript.

\section{Funding}

This research was funded by Lytix Biopharma AS and the Norwegian Research Council.

\section{Notes}

The authors declare the following competing financial interest(s): ØR is the CSO of the Lytix Biopharma AS. ØR and JSMS are minor shareholders in Lytix Biopharma AS.

\section{ACKNOWLEDGMENTS}

We are thankful for Randi Olsen's assistance during the electron microscopy study.

\section{ABBREVIATIONS}

DTNB 5,5-dithio-bis(2-nitrobenzoic acid)

HRP histidine-rich peptide

HRGP histidine-rich glycoprotein

$\mathrm{GSH}$ reduced glutathione

GSSG oxidized glutathione

$\mathrm{IC}_{50}$ half maximal inhibitory concentration

LMP lysosomal membrane permeation

$\mathrm{LR}_{50}$ half maximal disulfide linker reduction

SAMP short antimicrobial peptide

TEM transmission electron microscopy

UPLC ultra performance liquid chromatography

\section{REFERENCES}

(1) Kratz, F.; Müller, I. A.; Ryppa, C.; Warnecke, A. Prodrug Strategies in Anticancer Chemotherapy. ChemMedChem 2008, 3, 2053.

(2) Gerweck, L. E.; Seetharaman, K. Cellular pH Gradient in Tumor Versus Normal Tissue: Potential Exploitation for the Treatment of Cancer. Cancer Res. 1996, 56, 1194-1198.

(3) Tannock, I. F.; Rotin, D. Acid Ph in Tumors and Its Potential for Therapeutic Exploitation. Cancer Res. 1989, 49, 4373-4384.

(4) Makovitzki, A.; Fink, A.; Shai, Y. Suppression of Human Solid Tumor Growth in Mice by Intratumor and Systemic Inoculation of Histidine-Rich and $\mathrm{pH}$-Dependent Host Defense-Like Lytic Peptides. Cancer Res. 2009, 69, 3458-3463.

(5) Tu, Z.; Young, A.; Murphy, C.; Liang, J. F. The pH Sensitivity of Histidine-Containing Lytic Peptides. J. Pept. Sci. 2009, 15, 790-795.

(6) Zhang, W.; Song, J.; Zhang, B.; Liu, L.; Wang, K.; Wang, R. Design of Acid-Activated Cell Penetrating Peptide for Delivery of Active Molecules into Cancer Cells. Bioconjugate Chem. 2011, 22, 1410-1415.

(7) Poon, I. K. H.; Patel, K. K.; Davis, D. S.; Parish, C. R.; Hulett, M. D. Histidine-Rich Glycoprotein: The Swiss Army Knife of Mammalian Plasma. Blood 2011, 117, 2093-2101.

(8) Morgan, W. T. Interactions of the Histidine-Rich Glycoprotein of Serum with Metals. Biochemistry 2002, 20, 1054-1061.

(9) Morgan, W. T. Human Serum Histidine-Rich Glycoprotein. I. Interactions with Heme, Metal Ions and Organic Ligands. Biochim. Biophys Acta. 1978, 535, 319-333.

(10) Thulin, A.; Ringvall, M.; Dimberg, A.; Karehed, K.; Vaisanen, T.; Vaisanen, M. R.; Hamad, O.; Wang, J.; Bjerkvig, R.; Nilsson, B.; Pihlajaniemi, T.; Akerud, H.; Pietras, K.; Jahnen-Dechent, W.; Siegbahn, A.; Olsson, A. K. Activated Platelets Provide a Functional Microenvironment for the Antiangiogenic Fragment of Histidine-Rich Glycoprotein. Mol. Cancer Res. 2009, 7, 1792-1802.

(11) Ringvall, M.; Thulin, Å.; Zhang, L.; Cedervall, J.; TsuchidaStraeten, N.; Jahnen-Dechent, W.; Siegbahn, A.; Olsson, A. K. Enhanced Platelet Activation Mediates the Accelerated Angiogenic 
Switch in Mice Lacking Histidine-Rich Glycoprotein. PLoS One 2011, 6, e14526.

(12) Gorodetsky, R.; Mou, X.; Blankenfeld, A.; Marx, G. Platelet Multielemental Composition, Lability, and Subcellular Localization. Am. J. Hematol. 1993, 42, 278-283.

(13) Vanwildemeersch, M.; Olsson, A. K.; Gottfridsson, E.; Claesson-Welsh, L.; Lindahl, U.; Spillmann, D. The Anti-Angiogenic His/Pro-Rich Fragment of Histidine-Rich Glycoprotein Binds to Endothelial Cell Heparan Sulfate in a $\mathrm{Zn}^{2+}$-Dependent Manner. J. Biol. Chem. 2006, 281, 10298-10304.

(14) Dixelius, J.; Olsson, A. K.; Thulin, Å.; Lee, C.; Johansson, I.; Claesson-Welsh, L. Minimal Active Domain and Mechanism of Action of the Angiogenesis Inhibitor Histidine-Rich Glycoprotein. Cancer Res. 2006, 66, 2089-2097.

(15) Olsson, A.-K.; Larsson, H.; Dixelius, J.; Johansson, I.; Lee, C.; Oellig, C.; Björk, I.; Claesson-Welsh, L. A Fragment of Histidine-Rich Glycoprotein Is a Potent Inhibitor of Tumor Vascularization. Cancer Res. 2004, 64, 599-605.

(16) Lee, C.; Dixelius, J.; Thulin, Å.; Kawamura, H.; ClaessonWelsh, L.; Olsson, A.-K. Signal Transduction in Endothelial Cells by the Angiogenesis Inhibitor Histidine-Rich Glycoprotein Targets Focal Adhesions. Exp. Cell Res. 2006, 312, 2547-2556.

(17) Doñate, F.; Juarez, J. C.; Guan, X.; Shipulina, N. V.; Plunkett, M. L.; Tel-Tsur, Z.; Shaw, D. E.; Morgan, W. T.; Mazar, A. P. Peptides Derived from the Histidine-Proline Domain of the HistidineProline-Rich Glycoprotein Bind to Tropomyosin and Have Antiangiogenic and Antitumor Activities. Cancer Res. 2004, 64, 5812-5817.

(18) Jancsó, A.; Kolozsi, A.; Gyurcsik, B.; Nagy, N. V.; Gajda, T. Probing the $\mathrm{Cu}^{2+}$ and $\mathrm{Zn}^{2+}$ Binding Affinity of Histidine-Rich Glycoprotein. J. Inorg. Biochem. 2009, 103, 1634-1643.

(19) Richardson, A.; de Antueno, R.; Duncan, R.; Hoskin, D. W. Intracellular Delivery of Bovine Lactoferricin's Antimicrobial Core (RRWQWR) Kills T-Leukemia Cells. Biochem. Biophys. Res. Commun. 2009, 388, 736-741.

(20) Strøm, M. B.; Rekdal, Ø.; Svendsen, J. S. Antimicrobial Activity of Short Arginine- and Tryptophan-Rich Peptides. J. Pept. Sci. 2002, 8, 431-437.

(21) Weller, K.; Lauber, S.; Lerch, M.; Renaud, A.; Merkle, H. P.; Zerbe, O. Biophysical and Biological Studies of End-Group-Modified Derivatives of Pep-1. Biochemistry 2005, 44, 15799-15811.

(22) Aubry, S.; Burlina, F.; Dupont, E.; Delaroche, D.; Joliot, A.; Lavielle, S.; Chassaing, G.; Sagan, S. Cell-Surface Thiols Affect Cell Entry of Disulfide-Conjugated Peptides. FASEB J. 2009, 23, 29562967.

(23) Arpicco, S.; Dosio, F.; Brusa, P.; Crosasso, P.; Cattel, L. New Coupling Reagents for the Preparation of Disulfide Cross-Linked Conjugates with Increased Stability. Bioconjugate Chem. 1997, 8, 327-337.

(24) Saito, G.; Swanson, J. A.; Lee, K. D. Drug Delivery Strategy Utilizing Conjugation Via Reversible Disulfide Linkages: Role and Site of Cellular Reducing Activities. Adv. Drug Delivery Rev. 2003, 55, 199-215.

(25) Ghosh, A. K.; Fan, E. A Novel Method for Sequence Independent Incorporation of Activated/Protected Cysteine in Fmoc Solid Phase Peptide Synthesis. Tetrahedron Lett. 2000, 41, $165-168$. 